\title{
SISTEMES DE REPRESENTACIÓ GRÀFICA DE MOTS ÀRABS EN CATALÀ
}

Per

LLUIS B. POLANCO ROIG

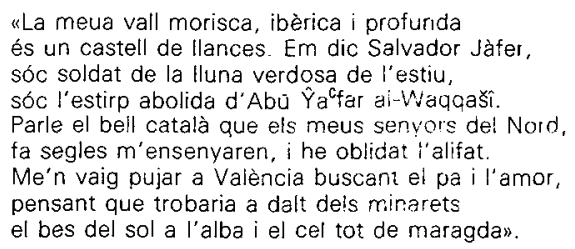

Oda estranya a València

L'objectiu d'aquests papers és donar a conéixer els sistemes de transliteració i transcripció de noms àrabs al català, elaborats per diversos equips de tècnics i recentment åprovats per la Secció Filològica de l'institut d'Estudis Catalans.

Abans, però, considerem convenient fer unes quantes observacions i un enquadrament d'aquestes sistemes dins l'evolució històrica i social de la llengua catalana, i la relació amb la llengua àrab.

\section{El marc social i històric}

1. LES TRANSCRIPCIONS AL.LÒGLOTES DINS ELS PROCESSOS DE NORMALITZACIÓ LINGÜISTICA

Convindria situar els sistemas gràfics que ací presentem dins el context del procés de normalització social del català.

Els sociolingüistes han observat, en efecte, que els anomenats proces- 
sos de normalització lingüística (Aracil 1965:31-34) -entenent com a tals "aquells processos que determinades comunitats lingüistiques, subordinades políticamente durant un llarg període històric, emprenen per tal de construir les condicons necessàries que assegurin la seva plena normalitat i estabilitat futures en tant que conjunt humà de llengua diferenciada» (Bastardas 1988: 187)- comporten sempre la fixació - anomenada codificació o normativització - d'unes normes lingüístiques destinades a perfilar una varietat lingüística amb el mínim de variació gratuïta de procedència regional, social o simplement individual. L'objectiu és d'obtenir la màxima eficàcia comunicativa a partir d'una "òptima disponibilitat de les formes que s'han d'utilitzar i en la previsibilitat de les formes amb què es pot entrar en contacte» (Lamuela 1984: 72-73), és a dir, a partir d'unes formes d'utilització i interpretació ràpida, senzilla i inequívoca. Aquesta codificació afecta igualmente el nivell lèxic - amb la compilació d'un diccionari normatiu -, el morfosintàctic - promulgant una gramàtica d'usos "correctes" - , i el fònico-gràfic - amb l'establiment d'unes normes ortogràfiques (i eventualment llur pronunciació preferent).

Com és sabut, tots aquests objectius han estat assolits per la \#lengua catalana dins la primera meitat d'aquest segle. En concret, l'ortografia unificada, potser l'aspecte que ací més ens afecta, va ser promulgada el 1913 (Normes ortogràfiques de l'Institut d'Estudis Catalans) (Segarra 1985a i 1985b) i assumida en un llarg procés que mena, al País Valencià, fins les Normes de Castelló de 1932 (Pérez Moragon 1982) i, a les liles Balears, a la incorporació, el 1935, del Diccionari Català-Valencià-Balear a la normativa unificada. El que ara convé destacar, en qualsevol cas, és que, amb aquesta reglamentació, el català, com tots els idiomes codificats, iniciava el cami d'un funcionament autònom, mitjançant un sistema de normes gràfiques coherent amb els propis condicionaments estructurals i diasistemàtics, i amb la própia tradició gràfica (Lamuela/Murgades 1984: 261-265; Segarra 1985b: 9-87).

Ara bé, l'abast dels sistemes gràfics que aci s'exposen s'ha de relacionar amb una major complexitat dels processos de normalització. Segons un model interpretatiu bastant conegut (Haugen 1983), aquests impliquen altres fases: prèvia a la codificació, hi ha, regularment, una selecció (selection), el decantament social per la promoció d'una determinada varietat. Però en aquests moments potser ens interessaran més els subprocessos posteriors. En primer lioc, l'anomenada vehiculació de la norma (implementation), una actuació més social (status planning, politique linguistique; Mackey 1986: 352) que no pas lingüística, dirigida a la difusió del coneixement i de l'ús del sistema educatiu i totes ies institucions socials (Administracio, mass media...)

El que cal fer notar, però, és que un dels objectius inexcusables de tota vehiculaciió - - i a fortiori de tota normalització lingüística - és la superació del que hom ha anomenat interposició o mediatització (Aracil 1983: 171-206) de la llengua dominant, que fa passar a través seu totes les relacions de la comunitat lingüistica subordinada amb el món exterior, tant en una direcció com en l'altra. Aquest fenomen, típic dels processos de minorització, afecta 
substancialmente les funcions lingüístiques de la societat -comunicació i representació socials (Lamuela 1984), on s'interposa l'al.lolecte- i té unes conseqüencies lingüístiques que, no per casualitat, són anomenats fenòmens d'interferència. Al País Valencià, per exemple, tota la informació internacional és encara servida en castellà als mass media - el circuit valencià de TV només s'atreveix amb la informació «local» - amb la qual cosa s'impedeix de veure adaptades a la pronúncia $i$, si convé, a la grafia de l'idioma propi les referències del món exterior, entre les quals, per exemples la realitat àrab i islàmica en general.

No és estrany, doncs, que, fa alguns anys, un dels primers diaris en català de la pre-democràcia transcrivís el nom del factòtum de la revolució iraniana com a «imam Jomeini», amb una grafia que provocaria en català una lectura aberrant. Altres pronúncies o escriptures usuals en el català col.loquial - «txiïta», per xii o xiïta; "El Cairo» per el Caire; "Tunes» per Tunis o Tunísia; "Argel" (amb velar fricativa) per Alger; "Fez" (amb interdental fricativa) per Fes-, moltes de les quals s'allunyen molt més de la llengua original que no les adaptacions genuines al català, denoten la clara empremta de la interposició del castellà.

Un altre tipus d'interposició detectable és la que genera sovint l'antiga llengua colonial de molts països àrabs - i molts altres del tercer món- que ve a coincidir en la majoria dels casos amb una de les interlingües més freqüents en la comunicació internacional. La conseqüència són grafies com «Gizeh", "Djibouti», "Djerba», "Meknès», "Kairouan», "Khartoum», "Marrakech», "Ouarzazate», "Oujda", etc. (Agencia Efe 1985: 78-79), les quals, si bé en algun cas la ironia fa més pròximes a les catalanes - cf "Fès", "Tunis" - altres vegades no deixen de menar a fenòmens curiosos. La lectura castellana per un catalanoparlant de grafies com "Ouarzazate" o "Gizeh", més enllà del grotesc destí a què estan condemnats certs noms innocents -i certes classes de parlants-, ens posen en guàrdia no sols sobre la complexitat dels fenòmens de minorització, sinó sobre els estralls, que potșer ni arribem a sospitar, dels laberíntics circuits de comunicació i representació social a nivell mundial (Aracil 1983: 194).

Del que cal adonar-se és que la vehiculació de qualsevol llengua - varietat codificada - en àmbits abans reservats a la llengua interposada fa patent la inadaptació - sempre provisional - de la varietat recentment promoguda per a satisfer les noves funcions. És aleshores que podem concebre una altra fase de la normalització: l'elaboració i cultiu de la llengua (elaboration o functional development), centrada, com abans la codificació, en actuacions predominantment lingüistiques (corpus planning, aménagement lingüistique) per tal de «dotar una llengua dels recursos lèxics i sintàctic propis dels estils que corresponen a aquests discursos i dels termes i de les fórmules necessaris per als llenguatges sectorials", entre els quals hi ha "activitats científiques, tècniques, administratives i comercials» $i$ «els discursos escrits i els públics», inclosos els difosos massivament pels moderns mitjans de massa escrits i audiovisuals (Lamuela 1984: 73-74). La determinació d'equivalències directes amb 
alfabets i sistemes fónico-gràfics diferents és part imprescindible d'aquesta elaboració, dins la qual caldria contextualitzar la preparació dels sistemes de representació de l'àrab en català, motiu d'aquestes línies.

El resultat de les fases comentades, i del procés d'estandardització, vessant lingüístic de la normalització (Lamuela 1984: 74-75), aboca a «l'estabilització del sistema de registres socials o, dit altrament, a la diferenciació estilística». Aquesta diferenciació estilística és la que principalment justifica, al meu parer, els diferents tipus de transcripcions que tot seguit veurem.

\subsection{EL MARC INTERNACIONAL}

No podem deixar de fer referència ací als intents que - al nivell els estats o internacionalmente - des de fa més d'un segle es fan per establir uns criteris homogenis de transcripció o transliteració (American Library Association 1885: Müller 1897), quan no propugnaven simplement l'adopció universal de l'alfabet llatí (Comission Internationale de Coopération Intellectuelle 1934). Aquest esforç, inicialment relacionat amb finalitats culturals o literàries, o de racionalització documental intraestatal, no sembla rebre, però, una empenta decisiva fins que no s'imbrica amb els interessos econòmico-polítics occidentals. En definitiva, es tracta de reproduir en el pla internacional el mateix procés que ha conduït de la construcció dels mercats nacionals a l'estandardització de les llengües modernes. Potser no és casualitat, doncs, que -en una evolució resseguible fins i tot en les denominacions - el màxim organisme de normalització internacional, consultiu de l'ONU, I'ISO (International Standardization Organization) siga el sucessor directe de I'ISA (International Federation of National Standardizing Associations), creada el 1926 precisament per "afavorir el comerç internacional a través del desenrotllament de l'estandardització de productes i processos" (Cabré 1985: 115). No endebades, I'ISO es crea el 1946 per «faciliter entre les nations les échanges de marchandises et les prestations de services et de réaliser une entente dans les domaines intellectuel, scientifique, technique et économique» (Cabré 1985: 115). En efecte, en tant que l'accés fluid a la informació més àmplia esdevé essencial per al control dels processos socials, econòmics i polítics, hom ha volgut esmerçar-hi els instruments més eficaços. És així que el "Comité Technique ISO/TC 46, Documentation», elabora primer uns "Principes Généraux de la Translittération", revisats posteriorment (ISO 1964), i després normes concretes per a cada idioma d'alfabet no-Ilatí, entre les quals les de l'àrab (ISO 1961), que ha servit de base per a les normes que s'exposen en aquests fulls.

La difusió d'aquestes "recomanacions" sembla lluny, però, d'ésser general. Hi ha, d'una banda, la inèrcia de les administracions occidentals, sovint previngudes davant una possible pèrdua d'àmbits d'influència lingüística i conseqüentment - cal dir-ho? - político-econòmica (Germany 1969; United States 1967; Gleichen/Reynols 1956; Agencia Efe 1985: 69-70). La principal resistència - encara que no la més organitzada - ve potser del costat de l'anglés. La tendència a la generalització d'aquesta llengua com a «interlingua» al nivell mundial es reflecteix també en els models de transcripció pro- 
moguts per l'ONU, o fins i tot pels mateixos països d'aquesta òrbita, com són la majoria dels de l'Extrem Orient -inclosa la República Popular de la Xina, que en la transcripció "pinyin» ha seguit criteris anglicitzants-, l'India o l'Orient Mitjà. En els respectius àmbits d'influència, té el mateix sentit la "ciril.lització» de nombroses llengües de I'URSS i les grafies afrancesades habituals en certs països àrabs i de l'Africa "francòfóna».

En realitat, ja hem vist com el que trobem en molts d'aquests casos, fruit de les recialles de la colonització, és una altra mena d'interposició, situada ací en la font dels missatges. I amb la particularitat que l'ús d'una «interlingua» regional o altra ha estat interioritzat i molt sovint oficialitzat, legalment o de fet, per l'estat respectiu. En el cas dels països àrabs, hom ha passat encara a una altra fase: les llengües occidentals impedeixen la intercomunicació interna. $\mathrm{O}$, el que és el mateix, afavoreixen l'ajornament indefinit de la normalització seriosa d'un àrab referencial comú (Grandguillaume 1983). L'anomenada intrusió (Aracil 1983: 201-203) està servida. Cada estat exporta els seus mots, no sols a través de la llengua dominant, sinó partint exclusivament de es diferents varietats locals, que semblen, a aquests efectes, incomunicades. La direcció és alhora interior: I'estat assumeix les formes gràfiques al.lòglotes i les converteix en moneda de canvi fins tot interna, de forma que aquelles esdevenen ja autòctones, també àrabs (o més aviat "algerianes", "tunisianes", etc.). Qui no s'ha estranyat davant la diversitat de grafies «llatines» oficials d'un mateix topònim des del Golf a l'Oceà? Evidentment, en el cas de poder arribar a relacionar-les.

El fet té implicacions importants per al tema que ens ocupa: en tot un seguit de transcripcions - sobretot les referides a l'època contemporàniacaldrà optar entre les formes afrancesades o anglicitzades i les classicitzants (literals). Chadly Benjedid o Xadli Ibn Jadid? No haurien de ser alternatives imaginàries. En tot cas, la inexorabilitat - transitòria? - de certes per no pensarhi i imaginar/decidir que podria no ser així. És un altre tema pendent de debat, on els professionals dels mitjans de massa tenen també a dir. Sorprén que els manuals de llenguatge periodístic català (Diari de Barcelona 1986: 44, 47; AVUI s.d.) hi hagen dedicat tan poc d'espai. Potser caldria revisar els criteris adoptats en les obres enciclopèdiques catalanes (GEC), que de vegades prefereixen explícitament les transcripcions «interposades» (Vilà i Valentí et alii 1983).

\subsection{LES RELACIONS ARAB-CATALA}

Les necessitats de precisar les equivalències del sistema fònico-gràfic del català amb el d'altres alfabets i llengües són encara molt àmplies, sobretot cara a la diversitat creixent d'àmbits d'ús on el català és present, no tinguts en compte - o molt parcialment - fins ara (GEC 1970-1983).

El cas de l'àrab presenta, com és ben sabut, un interés i una particularitat especials, des del punt de vista tant lingüístic com sociolingüístic. En primer lloc només cal recordar la llarga etapa de contacte directe entre àrab i 
català - primer de veïnatge, després de minorització de l'àrab dins dels territoris conquerits. La conseqüència fou sobetot un grau d'interferència léxica notable en ambdues direccions (Coromines 1936, 1980-88; Sanchis 1980: 77-90; Barceló 1984: 204-2101. Especialment remarcables són els rastres en la toponimia, particularment de l'Ebre cap avall (Barceló 1983). A partir d'aquests manlleus a l'àrab hom ha pogut reconstruir unes certes regularitats en l'adaptació al català (Moll 1952: 151-160; Sanchís 1980; Barceló 1983). Aquestes equivalències semblen tenir, tanmateix, ben poca utilitat per definir una transcripció actual: les tendencies són massa vacil.lants, les evolucions massa dràstiques i els mots originaris queden excessivament desfigurats. A més, el punt de partida era sempre l'arab col.loquial de Xarq Al-Andalus, i no el clàssic escrit.

A banda d'aquesta estricta interrelació lingüistica, el professor Mikel de Epalza ha sintetitzat molt bé darrerament la significació especial que ha tingut i té la civilització musulmana, i la cultura àrab en concret, per als catalanoparlants (Epalza 1984, 1986, 1987). Des del simple interés erudit pels mil $i$ un enigmes d'una llarga historia de convivència sovint problemàtica, al coneixement i la reivindicació d'un passat literari també sentit com a propi; de la valoració de l'empremta de molts segles en estructures socials, economiques i geogràfiques actuals a la rememoració festiva de tradicions i formes de vida proximes; de la redescoberta d'un parentiu entranyable amb els hereus dels nostres desterrats, a la sensació de compartir una important àrea geopolítica, unes determinades experiències de marginació i un futur de col.laboració més que convenient. També de l'altra banda tots aquests fets inclinen a veure en el mític Xarq al-Andalus quelcom més que una pura referència geogràfica.

El que és cert és que el món àrabo-islàmic suscita un renovat interés (Epalza 1984) i és tema d'una constant actualitat en tots els ámbits d'ús on el català va adquirint presència i que hom ha pogut sintetitzar darrerament (Epalza 1986: 194-195/ en:

1. Les publicacions erudites i universitàries sobre histdria, literatura, etc.

2. La divulgació cultural i històrica (institucional o nol sobre la realitat local o regional.

3. La premsa i en general els mitjans de comunicació de massa, orals - escrits.

4. La literatura, en traduccions o obres de creació narrativa o poètica. on el tema àrab és recurrent.

5. La literatura i el món festiu populars, amb representacions històricomitiques ("moros i cristians", etc.)

Sense ser els únics possibles, és a aquesta varietat d'àmbits de comunicació que caldrà facilitar unes normes de representació gràfica adequades.

\section{El procés cap a uns sistemes de transcripció}

\subsection{ANTECEDENTS EN CATALA}

Fins ara, a banda de les equivalències gràfiques aparegudes en obres ge- 
nerals (GEC 1970 - 83:2:321), més o menys seguides per altres publicacions, el costum sembla que ha estat elaborar sistemes de transcripció propis per a cada obra. Només per il.lustrar-ho breument citarem els sistemes de Joan Coromines (1936: 71 i 1980-88:I:XIV); de Manuel Sanchis Guarner (1975: 369-370 i 1980: 84-88). Les revistes filològiques de vegades han donat a conéixer els criteris que regularment, han seguit com la Revista Valenciana de Filologia (1951). Fora d'aquests àmbits erudits, pràcticament els predominants fins ara, en la resta dels esmentats adés hom ha vacil.lat entre l'adaptació d'algun d'aqueixos sistemes (Piera 1983: 10) i el simple calc del castellà.

\subsection{LA REUNIÓ TECNICA D'ALACANT}

El creixement dels mitjans de comunicació de massa en català, l'esplet d'una literatura morófila i la consolidació d'una meritoria revista alacantina especialitzada en temes aràbigo-valencians, Sharq al-Andalus. Estudios Arabes, han plantejat la necessitat d'unes normes de transcripci'o msés adaptades a les noves realitats, més precises, consensuades i difoses. En aquest ambient els professors de la Divisió d'Arab del Departament de Filologies Arab, Catalana i Francesa de la Universitat d'Alacant van encetar el procés que ara veiem en gran part enllestit, amb la convocatoria d'una reunió tècnica sobre la normalització d'arabismes en català.

La reunió tècnica va tenir lloc els dies 27 i 28 d'octubre de 1986 a la Universitat d'Alacant, amb la participació dels Drs. Joan Solà, Antoni Ferrando i Joan Miralles, catedràtics de Filologia Catalana de les Universitats de Barcelona, València i Balears; els Drs. Federico Corriente i María Jesús Rubiera, catedràtics d'Estudis Arabs i Islàmics de les Universitats de Madrid IComplutense) i Alacant; els Drs. Leonor Martínez, Dolors Bramon i Mikel de Epalza, professors titulars d'àrab i estudis islamics de les Universitats de Barcelona, Saragossa i Alacant; el prof. Lluís B. Polanco, de la Universitat de València; el Dr. Enric A. Llobregat, secretari del Consell Valencià de Cultura; el senyor Alberto Gómez Font, corrector de l'agencia EFE i el senyor Joseba Intxausti, de l'UZEl (Centre de Normalització Lexical de l'Euskera).

Va servir de fonamentada base de discussió una completa documentació que l'organització va facilitar i que contenia, a més de propostes de transliteració, transcripció i sobre aspectes concrets (vocals, geminades, article, accent tònic i gràfic, onomàstica, flexió dels adjectius), informació sobre altres sistemes de transcripció (Valencia/Gálvez/Oliva 1982; GEC; J. M. Millàs ¡ Vallicrasa; Revista Al-Andalus; Sanchis Guarner 1980 i Revista Valenciana de Filologial i unes interessants suggerències del Sr. Gómez Font -amb annexos sobre les solucions per al castellà. El debat, coordinat pel Dr. Epalza i amb la concurrència de professors ì estudiants de la Universitat d'Alacant, va arribar a unes conclusions que han estat concretades per Epalza (1986: 196-197) i Llúcia Martín i Pascua! (1987), als quals remetem.

Aquestes propostes - juntament amb suggerències trameses pels Srs. 
Gómez Font, Corriente, Solà i Polanco - van ser elevades a l'Institut d'Estudis Catalans, com a organisme amb reconeixement oficial per a la normativització del català. Una ponència delegada per aquesta institució va elaborar unes propostes definitives, que han estat la base dels "Sistemes gràfics de representació de mots àrabs en catalàn, recentment aprovats per la Secció Filològica de I'Institut d'Estudis Catalans (vegeu l'annex 1), i que exposem tot seguit.

\section{Exposició dels «Sistemes gràfics de representació de mots àrabs en català"}

\subsection{TIPUS DE SISTEMES GRÀFICS I FORMA DE PRESENTACIÓ}

a) Tal com es va decidir inicialment i ha estat aprovat finalment, es diferencien tres sistemes gràfics:

3.1. Transcripció fonemàtica “i literal (transliteració).

3.2. Transcripció simplificada.

3.3. Adaptació fònico-gràfica àrab-català.

b) Aspectes concrets, com la grafia de consonants geminades, de l'article àrab, de l'accent d'intensitat o dels noms propis, s'especificaran separadament en els apartats referits a cada sistema.

c) Per raons de brevetat i claredat no es farà constar l'origen de les solucions adoptades, ni la justificació de les normes.

\subsection{TRANSCRIPCIÓ FONEMÀTICA I LITERAL (TRANSLITERACIÓ)}

\subsubsection{Precisions generals}

a) Denominació. El nom de "transcripció fonemàtica" es justifica pel fet que intenta de reproduir amb la màxima exactitud els fonemes de l'àrab estàndard clàssic. Tenint en compte les característiques del sistema gràfic de l'àrab clàssic, on hi ha un alt grau de correspondència grafema-fonema, el mateix sistema és aplicable a grans trets - amb les escasses adaptacions precisades en el paràgraf següent - a l'anomenada «transcripció literal» - o «transliteració»-, que tracta de representar els caràcters gràfics, no els fonemes.

b) La «transcripció literal» o «transliteració» es diferenciarà de la "transcripció fonemàtica» fonamentalmente perquè:

- No representa l'assimilació «solar» de l'article.

- En l'anomenada "transcripció amb icrāb (flexió)" hom representa sempre l'anomenada alif wasla (sempre que corresponga, és clar, a un grafema efectivament present en la seqüència a transliterar).

c) Ús. Va adreçada a publicacions especialitzades o d'alta divulgació, amb un públic més o menys en contacte amb l'àrab, fet que, per exemple, 
explicaria la lımıtacıo de I' ús del guınet per marcar relacions sintàctiques sols dins una unitat gràfica àrab. Les possibilitats de la "transliteració» interessaran sobretot els estudis de paleografia, epigrafia i numismàtica.

d) Hom ha de considerar les normes enunciades respectivament sota els epígrafs "amb icrâb (flexió)» (apartat E-1) i "sense icrâb (flexió)» (apartat E-2) com a conjunts de normes alternatives, que convé no barrejar.

e) Hom segueix al màxim la redacció de la «Recommandation $R$ 233" de I'ISO (Organisation Internationale de Normalisation) (1961), amb alguns canvis de detall, que han estat incoporats a l'enunciat de les normes, i amb la unificació de la numeració de tots els subapartats, per facilitar la recerca dels diferents ítems.

f) Els grafemes entre parèntesis constitueixen alternatives secundàries, si hi ha impossibilitat de representar gràficament les formes preferents.

\subsubsection{Normes}

\section{A. CONSONANTS}

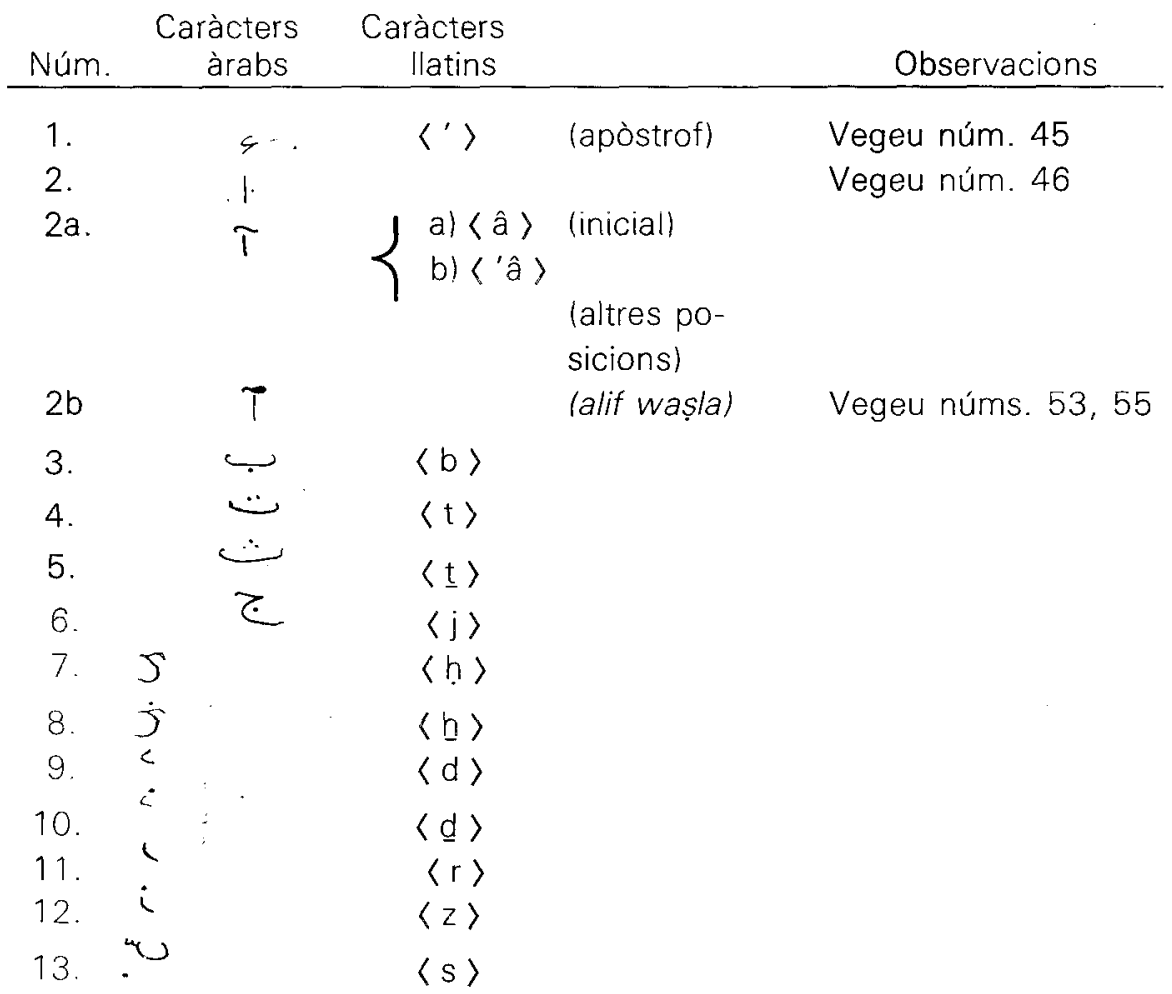




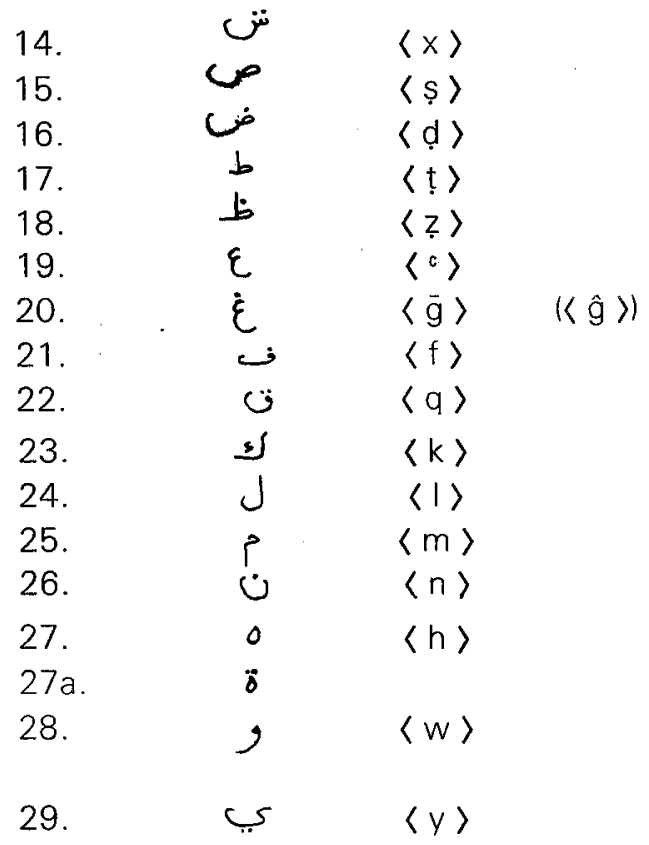

Vegeu núms. 52 i 57

Vegeu núms. 35, 41 , $45 d), 47,58$

Vegeu núms. 36,42 . $45 d), 47,58$

B. VOCALS I DIFTONGS

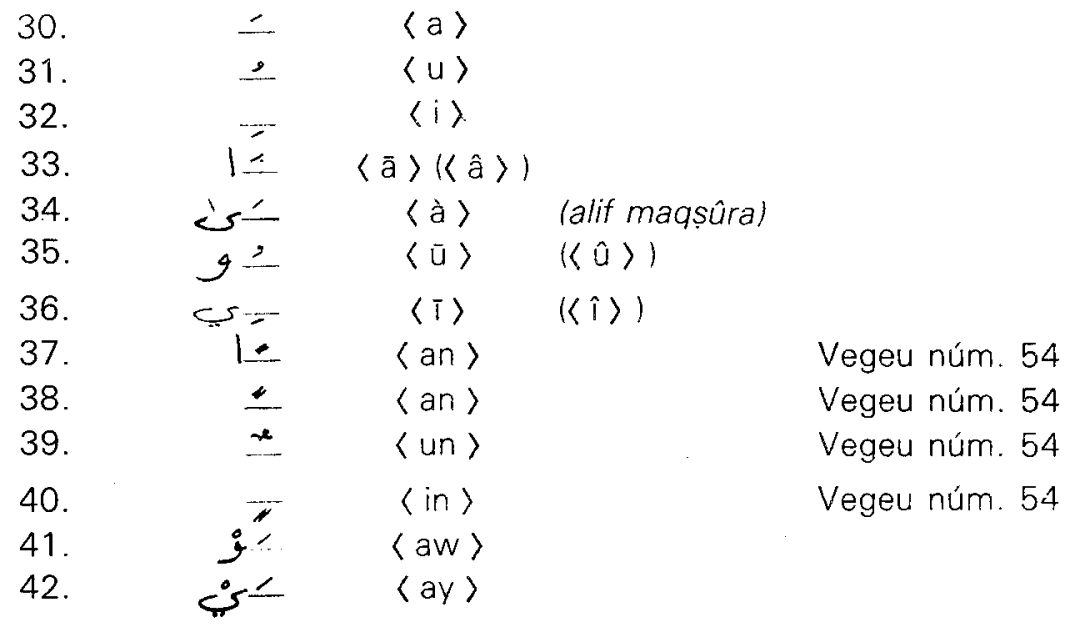

C. ALTRES SIGNES CONVENCIONALS 43.

no apareix

(sukün) 
44.

\section{E. NOTES GENERALS}

45. \& (hamza)

a) Inicial: No es transcriu: amin

b) Inicial: Pot transcriure's quanconvé distingir-la de la alif wașla: (Vegeu núms. 53, 55) 'amîn

c) Altres posicions: 〈' > (apòstrof): fu'âd

d) \, $s$, , amb hamza: No es transcriven: ra'à, li'am, su'al

46. Alif amb valor sols ortogràfic:

No es transcriu: (Vegeu núms. 3, 30, 33, 37, 44, 53, 55) mía, fach

47.,$i$ e amb xadda (fins $i$ tot seguint los vocals $u i i$, respectivament).

Ww i yy, respectivament (tret del cas del núm. 58): bawwâb, quwwâb, bayyâa

48. Assimilacions.

a) Article definit: Assimilat a les solars (excepte en cas de «transliteració»): ax-xams

b) En el cas de ahad tui semblants l'assimilació no es marca.

49. Guionet.

Emprat per separar elements gramaticalment diferents dins una unitat gràfica àrab, sobretot el nom (o elements nominals pronoms...) i el verb de:

a) L'article:

ax-xabâb, ar-Rușâfi, al-Qâhira

b) Partícules(preposicions, conjuncions) anteposades, com fa-ta-bi-kala- sa- a-:

la-hum, bi-hi, li-maliki, wa-bi xaraf 
c) Pronoms personals postposats:

baytu-hum, yaḍrubû-nâ

50. Lletres adaptades:

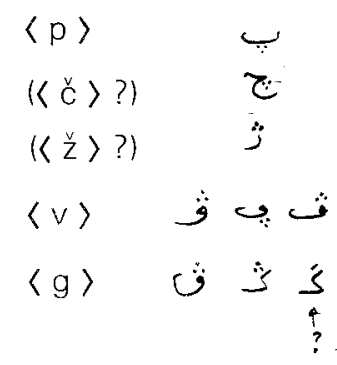

E-1. NOTES SOBRE LA TRANSCRIPCIÓ AMB IRAB (FLEXIÓ)

51. Terminacions flexionals (inclòs el tanwîn).

a) En general: Representades, amb lletres supraindexades o no:

bayt (baytu)

bi - nabiyyin (bi - nabiyyin)

b) En noms d'arrel amb radical final feble (detectives). Només la $\langle-n\rangle$

d'indeterminació serà - opcionalment- supraindexada:

qậụin (qâdin)

mánàn (macnàn)

52. Tấ marbûta

Representada amb una $\langle t\rangle$, supraindexada o no (d'acord amb la resta de terminacions flexionals):

al-madîna ${ }^{\text {tn }}$ (al-madînatu)

salâtun (salâtun)

53. Alif wașla

a) O no es transcriu:

bi-htimâmi, baytu l-maliki, mina n-nasi

b) O bé es transcriu (necessàriament en el cas de la transliteració) la vocal original corresponent amb el signe de breu -indicant que la vocal no es pronuncia:

bi-ľhtimâmi, baytu ăl-maliki, mina ăn-nâsi

\section{E-2 NOTES SOBRE LA TRANSCRIPCIÓ SENSE IRAB (FLEXIÓ)}

54. Vocals breus de la flexió nominal.

a) Amb el tanwîn: No es transcriuen:

Muhammad, Ibn Jubayr, misriyyîn, kitâbân

b) Davant un sufix promonimal: Es transcriuen (excepcionalment): baytu-hu, fi bayti-hi 
c) A la fi d'un nom o d'un títol: El sufix pronominal és transcrit amb la forma pausa (sense la vocal final) i, només en aquest cas, sense guionet de separació:

Ibn 'Abd Rabih

55. Alif wașla

Transcrita amb la vocal original (i, darrere vocal, opcionalment amb el signe de vocal breu):

bayt al-malik, min an-nâs, bi-ǐhtimân (bi-ihtimân), wa-uktub (wa-ǔktub)

56. Vocals breus finals de les conjugacions verbals, de sufixos pronominals i de partícules. Són transliterades:

mâ yatacallaqu, baytu-hu, maª, bayna

57. Tâ' marbûta

a) Estat absolut: No es transcriu: al-madîna

b) Estat constructe: Es transcriu amb una $\langle-t\rangle$ (superposada o no): madîna an-nabî (madînat an-nabî)

58. Seqüències $-i y y-i-u w w-$ finals.

Transcrits per $\langle\hat{i}\rangle \mathrm{i}\langle\bar{u}\rangle$ respectivament:

'arabî, ‘adû danî

59. ب començat per alif o no.

Sempre transcrit: Ibn.

\subsection{TRANSCRIPCIÓ SIMPLIFICADA}

\subsubsection{Precisions generals}

a) Denominació. Aquest sistema s'ha d'entendre com una simplificació, a tots els efectes, de l'anterior («transcripció fonética o literal»), fet que explica la denominació de «transcripció simplificada».

b) Ús. Va adreçada a obres de divulgació (històrica, política, lingüística, literària) i als mitjans de comunicació de massa. Els receptors, doncs, són un públic culte però no familiaritzat amb l'àrab. Intenta, per tant, reproduir els sons àrabs amb els grafemes habituals en català. Així mateix, està pensada per ser reproduïble amb els mitjans tipogràfics més a l'abast, per la qual cosa evita els signes diacrítics més inusuals.

c) En els aspectes no concretats particularment per a aquesta transcripció convindria seguir, sempre que siga possible, les normes especificades per a la «transcripció fonemàtica», i en concret les «Notes sobre la transcripció sense icrâb (flexió)", tenint en compte que els mots seran ara transcrits, en la majoria de casos, aillats del seu context. 
3.2.1. Normes

A. CONSONANTS

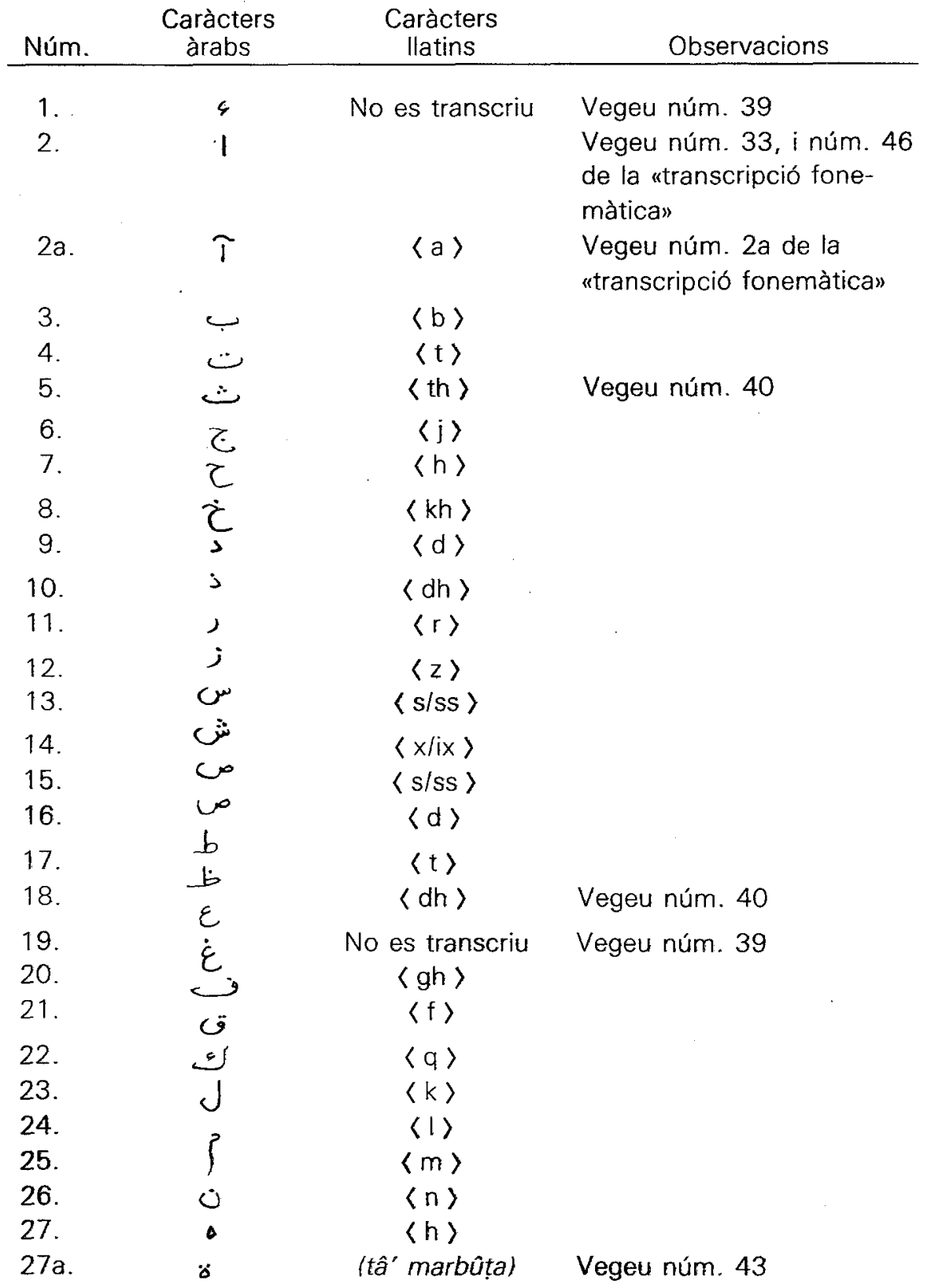


28.

29. $\langle w\rangle$

$\langle y\rangle$

Vegeu núm. 58 de la "transcripció fonemàtica"

Vegeu núm. 58 de la "transcripció fonemàtica"

B. VOCALS

\begin{tabular}{|c|c|c|c|}
\hline 30. & $=$ & $\langle a\rangle$ & Vegeu núm. 45 \\
\hline 31. & 1 & $\langle u\rangle$ & Vegeu núm. 45 \\
\hline 32. & $\tau$ & $\langle i\rangle$ & Vegeu núm. 45 \\
\hline 33. & $1=$ & $\langle a\rangle$ & \\
\hline 34. & $\dot{s}=$ & $\begin{array}{c}\langle\mathrm{a}\rangle \\
\text { (alif maqșūra) }\end{array}$ & \\
\hline & , & $\langle u\rangle$ & \\
\hline 6. & - - & $\langle i\rangle$ & \\
\hline
\end{tabular}

C. SIGNES CONVENCIONALS

37.

38.

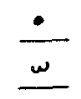

No apareix

Geminació de la consonat (xadda o taxdīd) (sukūn)

Vegeu núm. 46

\section{NOTES GENERALS}

39. 4 (hamza) i $\mathcal{E}$ (cayn) entre a $(e, 0)$ i $i$ ou.

No es transcriuen, però quan impedirien un diftong, cal marcar el hiatus amb el signe corresponent: accent o dièresi: 'al-Mustaín', 'raís', 'qàïd'

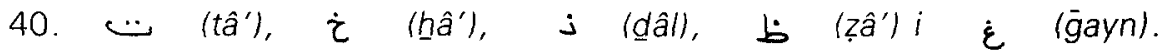

a) Es transcriuen $\langle$ th $\rangle,\langle k h\rangle,\langle d h\rangle,\langle g h\rangle$, respectivament: 'thawra', 'Ibn Khafaja', 'Dhi-n-Nūn', 'An-Nadhur', 'Ibn Ghàniya'.

b) Quan la conjunció de $\langle t, k, d, g\rangle$ amb $\langle h\rangle$ no ha de ser interpretada com a dígraf (provinent d'un sol grafema àrab), sinó com a dos grafemes corresponents a dues lletres àrabs, es pot marcar aquesta separació amb un punt volat enmig (con l'usat en la 〈I.l〉 geminada en català). A excepció, si s'escau potser, de la premsa periodica i altres publicacions amb impediments tipogràfics, i on serà inevitable, doncs, un cert grau d'ambigüitat: 'mud.hix', 'id-al-ad.ha', 'at.hama', 'fat.hí'.

\section{1. س (sîn) i 山 (șâd)}

a) Inicials, finals i davant 0 darrere consonant: $\langle s\rangle$

'Saïd', 'qasba', 'Munis, 'al-Mansur'. 
b) Intervocàliques o davant hämza o cayn - que no es transcriuenseguides de vocal: 〈ss $\rangle$ 'Hassan', 'Massud', 'assalu', 'Mussa'.

42.

a) Inicial, postconsonàntica, darrere $\langle i\rangle$ vocal: $\langle x\rangle$

'Banu Baixtagir', 'Xuhayr', 'xaykh', 'Jawxan'

b) Darrere vocala (fora de $\langle i\rangle)$ : $\langle i x\rangle$

'Marràkuix', 'ar-Raixid'

43. Tâ' marbûța

Es transcriu només en estat constructe:

'al-madina', 'madinat an-nabi'

44. Vocals i accent d'intensitat.

Les vocals (llargues o breus) es transcriuran sense signe de quantitat. Es representarà, tanmateix, 'accent d'intensitat segons les normes de l'accentuació gràfica en català, d'acord amb les següents regles de col.locació de l'accent prosòdic en l'àrab estàndard:

a) L'última síl.laba només porta accent en el cas de monosíl.labs tònics (generalment imperatius), del morfema dual i de les ultrallargues finals pausals, entre les quals caldria incloure els denominatius acabats en -f (provinent de - i y $\left.y^{n}\right)$ :

'Abu-Qarnayn', 'Abu-Jihad', 'al-magribi', 'Ibn Bassam'

b) La penúltima síl.laba porta sempre accent si és llarga:

'Al-Mudaffar', 'Banu Amira', 'Jàfar', 'Ibn Mufàwwiz'

c) En paraules de més de dues síl.labes que no tinguen les característiques anteriors l'accent es remunta fins que troba una síl.laba llarga o bé el principi de paraula:

'Al-Qàhira', 'al-Múqtadir'

45. Vocals flexives (nominals i verbals).

Es poden transcriure només en estat constructe 0 , preferiblement, no transcriure-les (vegeu la secció E-2 de la "transcripció fonemàtica»), atenent al caràcter aillat de la majoria dels mots d'aquesta transcripció.

46. Geminació de consonants (taxdîd o xadda)

Es fa generalment duplicant la consonant corresponent, amb les següents particularitats:

a) En la duplicació dels dígrafs no es repeteix $\mid a\langle h\rangle$ :

$\langle$ th $\rangle,\langle$ ddh $\rangle,\langle k k h\rangle,\langle g g h\rangle$ : 'al-Qaddhafí'

b) La doble $\langle 1\rangle$ resultant s'escriurà geminada: $\langle 1.1\rangle$ 
47. Article i partícules anteposades.

Es transcriuen unides sempre amb guionet al mot següent amb el qual formen una unitat gràfica en àrab:

'hamd li-L.lah', 'An-Nàssir', 'Dhi-n-Nun'

48. Onomàstica (noms propis)

Se seguiran els criteris següents, en els àmbits d'ús propis de la «transcripció simplificada»:

a) Es respectaran els antropònims i topònims amb una grafia tradicional reconeguda en català (GEC):

Marràqueix, Fes, Tunis, el Caire, Damasc, Riad, Rabat, Trípoli, etc.

b) En la resta de noms s'aplicaran en general les normes de la transcripció simplificada, -incloent-hi, és car, l'article-, excepte en el cas de lbn:

'Iqbal-ad-Dawla', 'Abu-Sufyan', 'Abd-ar-Rahman', 'Ibn al-Labbana', 'Ibn az-Zaqqaq'

d) En aquests antropònims (i ocasionalment topònims) composts units amb guionet, haurien d'anar en majúscula només aquelles parts que fossen noms propis - molts d'ells noms comuns habilitats - i no l'article, la preposició o els altres noms comuns, fora que quedessen com a inicials:

'Abd-al-Wahid', 'Al-Wahid', 'Abu-al-Mansur', 'Al-Mansur'

\subsection{ADAPTACIÓ FÒNICO-GRÀFICA ÀRAB-CATALÀ}

\subsubsection{Precisions generals:}

a) Denominació. No es tracta en aquest cas, evidentment, d'una transcripció, ja que, més que no l'estricta fidelitat al codi fònic o gràfic originari predomina la intenció d'adaptació al nostre, a costa de les imprecisions o variacions que calga. És, doncs, una simple adaptació.

b) Justificació. Intentaria regularitzar la introducció de manlleus de l'àrab. Hi ha hagut objeccions a aquest sistema, ja que un procés lent i sovint multiforme és difícil de conduir, ara que la introducció d'arabismes no és tan significativa, amb normes apriorístiques i sense la prova d'ús de la forma preferida col.loquialment i sense la prova d'ús de la forma preferida col.loquialment. Hom la proposa, doncs, com a material de treball per a posteriors estudis més aprofundits.

c) Ús. Podria tenir aplicació en l'adaptació de noms comuns ja usuals o que hom creu que caldria arribar a incorporar al cabal del lèxic comú -a banda d'aquells arabismes ja patrimonials que cal respectar absolutament en la forma normativa actual - , al llenguatje de la divulgació popular, de la literatura de creació i, potser, en el cas de noms propis molt integrats de la tradició àrab autòctona (noms de carrers, denominacions públiques, etc.). 


\subsubsection{Propostes}

a) Es parteix de la "transcripció simplificada».

b) Unificació de $\langle q\rangle i\langle k\rangle$ en $\langle c a$, que, qui, co, cu $\rangle$.

c) Eliminació de $\langle h\rangle$ com a part dels dígrafs $\langle$ th $\rangle,\langle k h\rangle,\langle d h\rangle,\langle g h\rangle$.

d) Simplificació de totes les lletres geminades de concurrència inhabitual en català (només quedarien, de fet, $\langle r r\rangle i\langle I . I\rangle$.

e) Pot considerar-se, en alguns casos, la caiguda de $\mid a\langle-n\rangle$ final de paraula.

f) Transformació de $\langle w\rangle i\langle y\rangle$ en $\langle u\rangle i\langle i\rangle$ respectivament.

g) Se segueix les regles generals sobre l'accent $\mathrm{i}$ l'onomàstica de la «transcripció simplificada".

h) L'article va unit, quan cal representar-lo, a la paraula següent directament, sense guionet. En cas de duplicació de $\langle 1\rangle$ caldrá escriure $\langle 1.1\rangle$.

i) Per a més dades, vegeu Martín i Pascual (1987: 380-383).

\subsection{PLURALS DELS NOMS D'ORIGEN ÀRAB}

La Dra. M. a Jesús Rubiera va elevar una consulta a I'Institut d'Estudis Catalans sobre el mots (substantius $i$ adjectius fonamentalment) d'origen àrab acabats en -í. L'IEC considera com a solució més raonable a aquesta qüestió tendir a regularitzar aquesta terminació lamb les flexions catalanes corresponents de gènere i nombre en els mots implicats - bastant nombrosos en català, a causa de l'encreuament amb el sufix llatí - ita o -ida, quan tinguen ja una llarga tradició, fet que no es dóna en tots els casos. Seria convenient, per tant, inventariar-los i fer-ne una revisió.

\section{Qüestions pendents}

Com hem vist, queden per resoldre alguns aspectes, sobretot gràfics, que potser recomanarien noves sessions d'estudi i d'elaboració de propostes. En podem destacar:

a) La transcripció d'alguns grafemes que, partint de l'alifat, representen sons no prevists en l'àrab clàssic.

b) Resulta problemàtica la transcripció a adoptar en el cas de topònims i sobretot antropònims actuals, divulgats internacionalment a través de transcripcions franceses o angleses, moltes ja usuals i fins oficials, com hem comentat, al mateix país d'origen. Una decisió catalanitzadora o classicitzant 
a ultrança potser faria inidentificables o poc convenients certs noms en determinats àmbits d'ús. Una decisió hauria de discutir-se dins el fenomen general de la «interposición i de les «llengües vehiculars», amb la participació dels països implicats i de professionals dels mitjans de massa.

c) Des d'un punt de vista lexicogràfic cal encara una revisió dels substantius $i$ adjectius derivats en $-i,-i d a$, -ita.

d) Queda pendent, també, aprofundir en nombrosos aspectes de l'anomenada uadaptació fònico-gràfica».

e) Així mateix, no s'ha plantejat encara un tema que té i tindrà cada vegada més incidència amb la proliferació dels mitjans àudio-visuals en català: la pronúncia (adaptada a la fonètica del català o de la llengua original?) dels noms d'origen estranger.

Aquest darrer aspecte, i en general tots els tractats en les pàgines anteriors, demanen una resposta meditada però àgil dels diversos professionals i experts, la qual podria constituir l'objectiu de nous debats tècnics. Una resposta que, per ser coherent i efectiva, potser s'haurà de qüestionar, no sols els mecanismes de recepció de la informació, sinó la relació global, a tots els nivells, de la nostra comunitat lingüística amb les altres.

\section{Referències}

AGENCIA EFE (1985). Manual de español urgente. Cátedra, Madrid.

AMERICAN LIBRARY ASSOCIATION (1885). "Committee on Transliteration Report" dins Lake George Proceeding, Library Journal, 10: 302-311.

ARACIL, Lluis V. 11965). Conflit linguistique et normalisation linguistique dans /'Europe nouvelle. Centre Europeen Universitaire [citat açi per ARACIL, LI. V. (1982) Papers de sociolingüistica. La Magrana, Barcelonal.

- (1983) . "Sobre la situació minoritàrian dins id. (1983) Dir la realitat. Edicions del Països Catalans, Barcelona, pp. 171-206.

AVUl (s.d.) Llibre d'estil de l'Avui (s.ll.).

BARCELÓ TORRES, $M^{a}$ del Carmen (1983). Toponímia aràbica del País Valencià. Alqueries i castells. Institut de Filologia Valenciana, València.

- (1984) Minorias islámicas en el País Valenciano. Historia y dialecto. Universitat de València، València.

BASTARDAS I BOADA, Albert (1988). "La normalització lingüistica: l'extensió de l'ús» dins BASTARDAS, A.ISOLER, J. (eds.) (1988) Sociolingüistica i llengua catalana. Empúries, Barcelona, pp. 187-210.

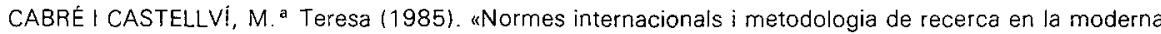
terminologia» dins DUARTE, C.IALAMANY, R. (eds.) (1985). Tradicio i modernitat en el llenguatge administratiu. Escola d'Administració Pública de Catalunya, Barcelona, pp. 111-129.

COMMISSION INTERNATIONALE DE COOPÉRATION INTELLECTUELLE (1934). L'adoption universelle des caractères latins (Dossiers de la Coopération Intellectuelle), París.

COROMINES, Joan (1936). "Mots catalans d'origen aràbic», Butlletí de Dialectologia Catalana, XXIV lara dins id. 11977) Entre dos llenguatges, III. Curial, Barcelona].

- (1980-88) Diccionari etimologic i complementari de la llengua catalana. Curial-La Caixa, Barcelona.

DIARI DE BARCELONA (1987). Un model de llengua pels mitjans de comunicació. Empuries, Barcelona.

EPALZA, Mikel de (1984). "Algurs aspectes de la morofília literària actual al País Valencià", Sharq al-Andalus. Estudios árabes, 1: 169-172.

- (1986) «El árabe y la lengua catalanan, Temas árabes, 2: 191-197 (Madrid, desembre 1986 ) 
- (1987) «Relacions dels Paisos Catalans amb el món musulmàn, Revista de Catalunya, 5: 49-62 (febrer 1987)

GERMANY. Bundesdruckerei (1969) Alphabete und Schriftzeichen des Morgen- und des Abendlandes; zum allgemeinen Gebrauch, mit besonderer Berücksichtigung des Buchgewerbes. Berlín.

GEC (1970-83). Gran Enciclopèdia Catalana. Ed. 62-Enciclopèdia Catalana, S. A., Barcelona.

GLEICHEN, E./REYNOLDS, J. H. (1956). Alphabets of foreign languages transcribed into English, according to the RGS // system. (2nd ed., revised). Permanent Committee on Geographical Names, London.

GRANDGUILLAUME, Gilbert \{1983\}. Arabisation et politique linguistique au Maghreb. Maisonneuve et Larose, París.

HAUGEN, Einar (1983). "The Implementation of Corpus Planning: Theory and Practice» dins COBARRUBIAS, J.IFISHMAN, J. (1983). Progress in Language Planning. International Perspectives. Mouton, Berlín.

ISO (Organisation Internationale de Normalisation/International Organisation for Standardization) (1961). Recommandation $1 S O$ «R233n. Système International pour la translittération des caractères arabes. (Comité Technique ISO/TC 46, Documentation).

- 11964). General Principles for the conversion of one written language into another. [ISO/TC 46 (sec. 426) 697 (Rev.)].

LAMUELA, Xavier (1984). «Fixació i funcionament de la gramàtica normativa en el procés d'estandardització de la llengua catalana" dins CABRÉ, M. T. et alii (eds.) (1984). Problemàtica de la normativa del català, P.A.M., Montserrat.

- MURGADES, Josep (1984). Teoria de la llengua literària segons Fabra. Quaderns Crema, Barcelona.

MACKEY, William F. (1986). "Planification linguistique, politique langagière et utilisation sociale des langues" dins RUIZ, J. I.JOZAMIZ, J. A. (eds.) (1986). Hizkuntza Minorizatuen Soziologia, Ed. Ttarttalo, Martutene.

MOLL, Francesc de Borja (1952). Gramàtica historica catalana. Gredos, Madrid.

MÜLLER, F. (1897). "Die Transcription fremder Alphabete», Sitzungsber. Phil.-Hist. Cl. Kaiserl. Akad. Wiss., 136.

PÉREZ MORAGON. Francesc (1982). Les normes de Castello. Eliseu Climent editor, València.

PIERA, Josep (1983). Els poetes aràbigo-valencians. Institució Alfons el Magnànim, València.

REVISTA VALENCIANA DE FILOLOGIA (1951). «Sistema de transcripción fonética de la Revista Valenciana de Filología», R.V.F., 1, 3 (juliol-setembre. 1951: 169-177).

RUBIERA, M. ${ }^{a}$ Jesús/EPALZA, Mikel de (1987). Xàtiva musulmana (segles VIII-XIII) Ajuntament de Xàtiva, Xàtiva.

SANCHIS GUARNER, Manuel (1975). "Ėpoca musulmana», dins TARRADELL, M.ISANCHIS GUARNER M. 11975). Història del País Valencià, 1. Ed. 62, Barcelona.

- (1980). Aproximació a la història de la llengua catalana. Salvat, Barcelona.

SEGARRA, Mila (1985a). Història de l'ortografia catalana. Empúries, Barcelona.

- (1985b) Història de la normativa catalana. Enciclopèdia Catalana, Barcelona.

UNITED STATES. Government Printing Office (1967). Style Manual (revised edition), Washington.

VALENCIA, Rafael/GÁLVEZ, M. ${ }^{a}$ Eugenia/OLIVA, Diego (1982). "Una propuesta para la sistematización de la transcripción de textos y nombres árabes en trabajos de numismática andalusí», Acta numismatica, 12: $131-137$

VILȦ I VALENTÍ, J. et alii (1983). Atlas Universal Català. Enciclopèdia Catalana, S. A., Barcelona. 